analogy of the rash of scarlet fever, the effect of medicines directed to other organs, the extraordinary symmetry, and even from the hereditary character of the disease.

Its choice of the inner surfaces and folds of the limbs may be due to the fact that the protective epidermis is thinner there, and germs are less liable to be brushed away than on the outer sides, but after all there are many intense inflam. mations of the skin which do not go on to eczema. There is more than a mere inflammation concerned in the process. Some perversion of function like the mucoid degeneration seen in catarrhs of the mucous membranes replaces the normal activity of secretion. Frequently, as this may commence from a local injury and spread over a large area, there does seem to be a class of cases where a widely circulating poison renders unstable the cells over the entire superficies of the body, just as a single meal of bad fish induces a universal attack of urticaria.

\section{DIABETIC COMA.}

What are the causes of diabetic coma? and How should we treat it? are two questions that hitherto have found no very satisfactory answer.

It has been supposed that the immediate cause of diabetic coma was acetonæmia, the action of aceton having an effect very similar to that of ether and alcohol, though not quite so powerful. But the amount of aceton circulating in the blood is not sufficient to account for the symptoms; moreover, as the comatose condition comes on, the aceton is not infrequently diminished, its less oxidised predecessor, oxybutyric acid, being more abundant, the latter having no narcotic action. Minkowski's and Stadelmann's explanation of this is that the blood is unable to form the necessary loose chemical combination with the carbonic acid in the tissues, owing to its alkaline salts being fixed by oxybutyric acid and other acids resulting from incomplete oxidation of proteids. Thus the carbonic acid is not conveyed by the blood to the lungs and eliminated. Dr. Schmitz has recently published his views as to the nature and causes of diabetic coma.*

Dr. Schmitz recognises two distinct causes. The first is weakness of the heart's action, caused by the effect of the sugar in the blood on the muscular fibres of the heart. In diabetic subjects, even when fat and seemingly in good condition, the body muscles are lax and soft, and the results are feeble gait and weariness easily produced. The heart muscle, he argues (and post-mortems support him), is in a similar condition, also suffering from degeneration of its fibres. The cyanotic face, the quick breathing, and the slow, small pulse, getting quick and irregular with the slightest exertion, point in that direction. Then the cardiac impulse is hardly perceptible, the area of the heart's dulness is increased in breadth, and, on auscultation, not only at the apex, but on the aorta, the first sound is anything but clear. Suppose such a heart is wearied out by over exertion, the result is that the breathing is affected, the appetite disappears, the head suffers from giddiness, pain, and an inclination to vomit, and if no precautions are taken, or prove of no avail, the arteries get more and more empty, the veins more and more full, and carbonic acid accumulates in the blood, somnolence steals on, coma succeeds, and the patient dies poisoned. In such cases the line of treatment is plain. Anything exciting the heart, medicinal or other, must be avoided. Hill climbing, stair climbing, long walks, early rising, Venus and Bacchus in excess are all to be avoided, as also are bromide of potassium, all combinations of potassium, salicyl, antipyrin, antifebrin, and hot baths. Also narcotics, except when absolutely necessary, and then carefully used. Nutritious, but easily digested food, a moderate amount of alcohol, fresh and invigorating air-these are the best drugs. Of * Schmitz, Berl. Klin. Woch., Aug. 25th, 1890; Stewart, Med. Chron.,
Nov., 1890. course, one must not lose sight of the ordinary diabetic treatment; the above refers to cardiac failure. In a pressing case the patient is to be kept in the recumbent position, and must neither stand up nor sit up, even for stools and urinating. Stimulants by the mouth, or, preferably, if apt to cause vomiting, subcutaneously (e.g., musk and camphor). The best stimulant of all is black coffee. With alcohol in large doses it is necessary to be careful, on account of the succeeding depression favouring collapse. The neglected castoreum sibiricum, not canadense, he considers a very good stimulant. The great danger lies in letting the patients up too soon, and the great difficulty is keeping them in bed long enough.

The second form of diabetic coma he describes as an acute self-poisoning, which has been named, although not correctly, acetonœmia. This condition is preceded by symptoms mistaken for indigestion, or slight gastric catarrh, with great weariness and sleepiness. The sleep, like that of drunkenness, leaves the patient more weary, feeble, and heavyheaded than before it. There is usually constipation, sometimes diarrhcea, the tongue coated and dry, and the breath smells badly. In about two days he becomes so drowsy that it requires a loud call to rouse him; he seems peevish, and hardly answers a question, and quickly relapses into his sleepy condition. He complains of colicky pains in the abdomen, which become very severe. After violent efforts he vomits some green-coloured fluid, the pain is then somewhat relieved, and he falls asleep until another attack.

The heart and lungs on examination reveal nothing abnormal. The pupils are generally contracted, and react but slightly. Towards the end violent clonic and tonic spasms set in, and death follows in deep coma. The colic, the high temperature, and the clear heart sounds distinguish this form of coma from that produced by cardiac failure. The treatment consists in clearing out the bowels, constipated or not, with one or two tablespoonfuls of castor oil. "The poison, be it ptomaïne or toxine, or whatever else, is a product of decomposition in the bowel." After a thorough purging, resulting in a profusion of black, foul, foetid stools, recovery is remarkably quick. Of eight cases, all equally bad, four not treated with the oil died, and four treated with it speedily recovered.

The clinical success reported by Dr. Schmitz go a long way to support his views as to treatment, but a large number of cases are unfortunately always fatal in spite of all treatment. Dr. Saundby t reports that in a case under his care the inhalation of oxygen was tried without success, while the subcutaneous injection of strychnine and intraperitoneal injection of an alkaline solution also failed.

\section{THERAPEUTICS.}

\section{GELSEMIUM SEMPERVIRENS.}

The rhizome and rootlets of the Gelsemium sempervirens, or Carolina jasmine contain the active principle gelsemine. The plant is one of the most beautiful tree creepers of Florida, having a yellow flower which is said to be poisonous. Gelseminic acid was first investigated by Wormley, more recently by Robbins, who concluded that it was identical with rsculin, the glucoside of Esculus hippocastanum, the common horsechestnut. The drug owes its therapeutical properties, however, to the alkaloid gelsemine, the formula of which is stated to be $\mathrm{C}_{12} \mathrm{H}_{14} \mathrm{NO}_{2}$.

The so-called physiological, but more correctly termed pathological, action of gelsemine has been observed in many cases of poisoning by gelsemium. Moderate doses give rise to injection of the conjunctivæ, pain in the eye-lids, and contracted pupils, with slight ptosis. A sense of not un. pleasant languor, with muscular weakness, and a consequent t Saundby, Medical Annual, 1890. 
difficulty in keeping the jaw closed are early symptoms of poisoning.

Larger doses affect particularly the motor tracts of the spinal cord at first, loss of voluntary movement with stagger. ing, followed by motor paralysis, and finally tetanic convulsions resembling strychnine poisoning. Previous to the onset of tetanus fibrillary movements are observed in the muscles, and the tetanic convulsions differ from those produced by strychnine in occurring rhythmically and not being persistent, and there is marked implication of the respiratory centres. The tetanic convulsions are soon followed by persistent paralysis. The first nerve affected in gelsemium poisoning is the sixth at its termination, and thus, by paralysis of the external rectus muscle, internal strabismus and double vision is produced. This is soon followed by implication of the third with ptosis and dilated pupils. In the earlier stages the pupils are contracted. Dizziness, numbness, or anæsthesia, or a marked lowering of the temperature. It has a depressing action on the heart, and the pulse rate is diminished, probably by its paralysing action on the excitomotor ganglia of the heart. Its action on the respirations, which become shallow, laboured, and arrhythmical are likewise the result of implication of the respiratory centres, death resulting from failure of respiration. Berger, however, has stated that death results from paralysis of the vagus.

The therapeutical applications of gelsemium may be arranged under the following headings :

In spasmodic affections it has been employed on account of its paralytic action on the spinal centres. It has been recommended for tetanus. It has been administered in local spasmodic affections with success, such as blepharospasm, spasmodic torticollis, painters' cramp, and also in chorea. Dr. Read has reported a case of tetanus which was cured by forty-drop doses of tincture of gelsemium every two hours as long as the convulsions recurred, followed by twenty-drop doses every two hours for several days. Bartholow recommends the tincture of gelsemium in certain forms of convulsive or spasmodic cough, and in acute inflammations of the lungs and plura, he thinks it may do good by diminish. ing the activity of the respiratory functions.

Gelsemium is most frequently employed in neuralgic affections. It is in neuralgias of the fifth nerve that it is most certain in action, such as facial neuralgias, tic douloreux, and inferior dental neuralgia. But it has also proved success. ful in ovarian and intercostal neuralgia, and in myalgia. The dose should be about five or ten minims of the tincture repeated every hour till relief is obtained, but inasmuch as the strength of the tincture varies much, as well as individual susceptibility to the drug, it is safer to begin with doses of two to five minims, gradually increasing it. Early symptoms of poisoning should be carefully watched for, as several fatal cases have been reported from overdosage.

Gelsemium has been used in America as a febrifuge, although in such a role it has never found much favour. It is hardly likely to replace the very numerous, efficient, and safe antipyretics that have been introduced within the last five years, but it is useful in some of the febrile attacks of children.

As a hypnotic it is certainly wortby of consideration. In insomnia from exhaustion, or the result of excitemen, the dose must be small, half to two minims, or not exceeding five, and may be repeated at intervals of an hour. It probably acts as a gentle stimulant to the exhausted nerve centres.

\section{BOOKS RECEIVED.}

THIN, JAMES, Edinburgh.

"The Intra-Oranial Oirculation and its Relation to the Physiology of the Brain." James Cappie, M.D. Price 7s. 6d. Wright aNd Oo., Bristol.

“ The Medical Annual and Practitioner's Index for 1891."

\section{NEW DRUGS, APPLIANCES, AND THINGS MEDICAL.}

[All preparations, appliances, novelties, etc., of which a notice is desired, should be sent for The Editor, to care of The Manager, 140, Strand, London, W.0.]

\section{SCRUBB'S CLOUDY HOUSEHOLD AMMONIA.}

This is a useful ammoniacal preparation of full strength, which the busy housewife will find always ready to hand. For cleansing purposes, whether for the wash-tub, or for plate, or for clothing, it will be found a decided acquisition to the store cupboard. A little added to the hot bath will aid in removing that excessive feeling of fatigue which prolonged exercise gives. We have long recommended ammonia in a foot bath of very hot water as the best restorative for the tired legs and feet of those who have to stand a greater portion of the day. The present preparation has yielded good results in our hands in this respect. We have no doubt it will prove equally useful in the treatment of gnat bites and insect stings of all sorts, and for the thousand and one purposes for which a liquid form of ammonia is required. The idea is ingenious, and we fancy that this is the only liquid ammonia in the field other than pharmaceutical preparations. It ought to prove a success. The offices of the firm who produce it are in Red Cross Street, E.C., and they will be pleased to forward samples to any medical man who will send a request for them to the office.

\section{AESCULAP WATER.}

Among tried, proved, and safe remedies, Esculap Water continues to hold its own. It is, indeed, if possible, still more approved and used by the medical profession than it has ever been. It well deserves this universal confidence. Asculap has all the qualities which an aperient should possess. It is mild but effective, prompt in action, but not worrying; wholesome and safe. As a simple and pure saline it has no superior and few equals. The range of its use is very wide. Men, women, and children may alike take it, and under almost any circumstances. It is surprising that the springs do not become exhausted and that the water does not change in quality. We have made particular enquiries on this subject, and find that the results of analysis are practically constant. In the interests of those who need and value a mild and safe aperient we cannot but hope that Esculap will continue to remain as effective, wholesome, and safe as it has always hitherto proved itself to be.

\section{EDITOR'S LETTER-BOX,}

[Our correspondents are reminded that prolixity of statemont is a great bar to pnblication, and that brevity of style and conciseness of state. ment greatly facilitate early insertion.]

THE DULNESS OF DOMESTIC SERVICE.

SIR,-The writer of the Annotation which appeared in your paper of the 9 th inst., on "The Dulness of Domestic Service," is, I think, mistaken about the want of interest taken by mistresses now in the welfare of their servants, for in order to keep one in the present day, we must give little work, good wages, and many "intervals of leisure." Whether the mistress be a conscientious person or not, this has become a matter of necessity. It seems more likely that the deterioration of domestic servants is due to their want of conscience and thoroughness, for whereas our mothers will tell us of loyalty, and even devotedness, in the past, we have now to be satisfied with "eye-service." I think this will remain so until " sweet reasonableness" asserts itself among domestic servants, and they, as well as we, try to understand the "give and take" of life.-Yours truly,

May 18, 1891. 